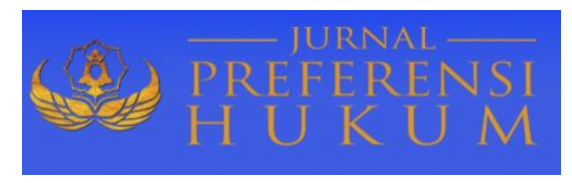

Jurnal Preferensi Hukum | ISSN: XXXX | E-ISSN: XXXX

Vol. 1, No. 2 - September 2020, Hal. 208-213| Available Online at https://www.ejournal.warmadewa.ac.id/index.php/juprehum

DOI: http://doi.org/10.22225/jph.v1i2.2361.208-213

\title{
BHABINKAMTIBMAS DALAM MENJAGA KEAMANAN DARI PAHAM RADIKALISME DI WILAYAH HUKUM POLSEK DENPASAR TIMUR
}

\author{
Ni Nyoman Septiana Dewi, A.A Sagung Laksmi Dewi, I Made Minggu Widyantara \\ Fakultas Hukum Universitas Warmadewa, Denpasar-Bali, Indonesia
}

\begin{abstract}
Abstrak
Bali merupakan salah satu destinasi wisata; banyak yang datang untuk berlibur dan menikmati indahnya pulau Dewata Bali, baik warga Negara asing maupun wisatawan local. Banyaknya wisatawan lokal maupun warga Negara asing yang datang ke Bali dimanfaatkan oleh segelintir orang untuk melakukan tindakan kejahatan, seperti yang baru-baru ini terjadi di wilayah hukum Polsek Denpasar Timur. Tim gabungan Densus 88 Mabes Polri, Satgas CTOC dan Brimob Polda Bali, pada hari Selasa 26 Juni 2018 pukul 20.30 WITA, menggrebek salah satu rumah di Jl. Gandapura terkait Kelompok Radikalisme. Kajian ini mengeksplor dua isu yakni usaha Bhabinkamtibmas dalam menjaga keamanan dari paham Radikalisme dan faktor-faktor yang dapat mempengaruhi berkembangnya paham radikalisme. Metode dari penelitian yang digunakan dalam kajian ini ialah penelitian hukum normatif dengan menggunakan pendekatan perundang-undangan. Bhabinkamtibmas adalah petugas kepolisian yang bertugas di tingkat desa sampai dengan kelurahan dengan mengemban fungsi preventif dengan cara bermitra dengan warga masyarakat, dan mempunyai peran penting untuk mencegah berkembangnya paham radikalisme. Simpulan dari hasil penelitian ini adalah radikalisme muncul sebagai paham atau ideologi yang menuntut perubahan dan pembaruan sistem sosial dan politik dengan cara kekerasan (Sztompka, 1993; Odea, 1996). Sebagai usaha Babhinkamtibmas untuk mencegah berkembangnya faktorfaktor yang dapat menyebabkan paham radikalisme, bimbingan dan penyuluhan hukum dan Kamtibmas diberikan untuk meningkatkan kesadaran hukum dan Kamtibmas dengan menjunjung tinggi Hak Asasi Manusia (HAM) di wilayah hukum Polsek Denpasar Timur.
\end{abstract}

Kata Kunci: Babhinkamtibmas; Keamanan; Radikalisme

\begin{abstract}
Bali is one of the tourist destinations; many come for a vacation and enjoy the beauty of the island of Bali, both foreign nationals and local tourists. The number of local tourists and foreign nationals who come to Bali is used by a handful of people to commit crimes, as recently happened in the jurisdiction of the East Denpasar Police. The joint team of Densus 88 Police Headquarters, Task Force CTOC and Brimob Polda Bali, on Tuesday, June 262018 at 20.30 WITA, raided one of the houses on Jl. Gandapura related to Radicalism Group. This study explores two issues, namely Bhabinkamtibmas efforts in maintaining security from radicalism and the factors that can influence the development of radicalism. The method of research used in this study is normative legal research using a statutory approach. Bhabinkamtibmas are police officers who work at the village to subdistrict level and carry out a preventive function by partnering with community members, and have an important role in preventing the development of radicalism. The conclusion from the results of this study is that radicalism appears as a notion or ideology that demands change and renewal of social and political systems by means of (Sztompka, 1993; Odea, 1996). As an effort by Babhinkamtibmas to prevent the development of factors that can cause radicalism, legal guidance and counseling and social security are provided to increase legal awareness and social security by upholding human rights (HAM) in the jurisdiction of the East Denpasar Police.
\end{abstract}

Keywords: Babhinkamtibmas; Security; Radicalism

\section{PENDAHULUAN}

Negara Kesatuan Republik Indonesia merupakan Negara Kesatuan yang berdasarkan atas hukum (rechtsstaat), tidaklah berdasarkan atas kekuasaan semata (machtsstaat) (Kansil, 1989). Pernyataan ini secara nyata tercantum dalam penjelasan Umum Undang-Undang Dasar Negara Kesatuan Republik Indonesia Tahun 1945. Ini menunjukan bahwa Indonesia merupakan Negara hukum. 
Dijuluki Negara hukum, Negara Indonesia menerima hukum sebagai Ideologi guna menciptakan keamanan, keadilan, ketertiban, juga memberikan kesejahteraan bagi seluruh warga negara kesatuan republik Indonesia. Setiap perubahan hukum harus sesuai dengan aturan-aturan yang ada tanpa terkecuali. Hukum adalah rule of the game bagi semua interaksi manusia dalam hidup berbangsa dan bernegara, agar masyarakat menghormati hukum, maka hukum itu harus berwibawa agar dapat dipatuhi oleh semua subyek hukum.

Indonesia memberlakukan hukum pidana untuk menjamin terlaksananya perlindungan hukum kepada masyarakat secara umum, dimana dalam prakteknya hukum pidana mengacu pada kitab Undang-undang Hukum Pidana (selanjutnya disebut KUHP). KUHP terdiri atas 3 (tiga) buku yakni buku kesatu tentang Ketentuan Umum, buku kedua Polri merupakan alat pemelihara keamanan Negara yang mempunyai tugas yaitu menjaga keamanan dan ketertiban masyarakat, juga menegakkan hukum, serta memberikan pengayoman, pelayanan dan perlindungan terhadap masyarakat, menegakkan hukum, serta memberikan perlindungan, pengayoman, dan pelayanan kepada masyarakat untuk menjaga dan demi terpeliharanya keamanan dan juga ketertiban NKRI (Sinambela \& Dkk., 2006). Polri merupakan Kepolisian Negara Republik Indonesia yang mempunyai tujuan guna mewujudkan keamanan dan ketertiban masyarakat. Polri diwajibkan untuk mampu menertibkan seluruh lapisan masyarakat dengan mengatasi berbagai permasalahan social salah satu contohnya adalah mengenai Radikalisme. Radikalisme merupakan suatu paham sosial/politik yang dalam usaha mencapai tujuannya menggunakan cara-cara kekerasan (Jainuri, 2016).

Bali sebagai destinasi wisata, banyak warga Negara asing maupun lokal yang dating untuk berlibur di Bali. Bali juga dikenal dengan sebutan Pulau Dewata, Pulau Seribu Pura, atau Pulau Surga. Banyaknya wisatawan lokal maupun Mancanegara yang datang ke Bali maka dimanfaatkan oleh segelintir orang melakukan tindakan kejahatan, seperti contohnya yang terjadi baru baru ini di wilayah hukum Polsek Denpasar Timur Polresta Denpasar Tim gabungan Densus 88 Mabes Polri, Satgas CTOC dan Brimob Polda Bali pada hari Selasa 26 Juni 2018 pukul 20.30 Wita menggrebek salah satu rumah di jalan Gandapura. Rumah tersebut di tempati pria asal Jawa Timur berinisial BE (45 tahun) terkait Kelompok Radikalisme. Berdasarkan Informasi yang diperoleh saat dilaksanakan penggeledahan di rumah tersebut ditemukan barang berupa puluhan magazen berisi peluru aktif, beberapa buku dan senjata laras panjang. Penggeledahan tersebut disaksikan juga oleh aparat dusun dan tokoh masyarakat setempat. Bali merupakan tempat berkumpulnya berbagai wisatawan dari seluruh dunia.

Berkembangnya pariwisata sebagai andalan perekonomian khususnya di Bali bertumpu pada potensi alam, potensi budaya, dan kehidupan masyarakatnya maka dari itu sangat penting menjaga masyarakat dari paham Radikalisme agar pertumbuhan ekonomi masyarakat khususnya di Bali tetap terjaga karena jika masyarakat terhindar dari paham Radikalisme otomatis kehidupan bermasyarakat akan menjadi aman dan damai sehingga wisatawan yang ingin berlibur merasa aman dan nyaman dalam berlibur. Kajian ini menelaah tentang usaha yang dilakukan Bhabinkamtibmas dalam menjaga keamanan dari paham radikalisme dan faktor-faktor yang dapat mempengaruhi berkembangnya paham radikalisme.

\section{METODE PENELITIAN}

Penelitian pendekatan masalah yang digunakan dalam kajian ini ialah penelitian hukum normatif, yaitu penelitian hukum yang berasal dari pengkajian bahan-bahan hukum dari berbagai peraturan perundang-undangan dan bahan lain dari berbagai literatur, yang didapatkan dari perpustakaan ataupun studi dokumen penelitian ini lebih banyak dilakukan terhadap data yang bersifat sekunder yang ada di perpustakaan (Mustofa, 2007). Suatu penelitian normatif harus menggunakan pendekatan masalah, Dengan kata lain penelitian ini menggunakan atau meneliti bahan pustaka atau bahan hukum sekunder. Nilai ilmiah suatu pembahasan masalah ilegal issue yang akan diteliti sangat tergantung kepada cara pendekatan yang digunakan. Jika cara pendekatan tidak tepat, maka bobot penelitian tidak akurat dan kebenarannya dapat diragukan.

Sumber bahan hukum terdiri atas peraturan perundang-undangan:

a) Peraturan Kepala Kepolisian Negara Republik Indonesia No. 3 Tahun 2015 tentang Kepolisian Masyarakat. 
b) Undang-undang Republik Indonesia (Perppu) No. 2 Tahun 2017 tentang Organisasi Kemasyarakatan.

c) Undang-undang No 5 tahun 2018 tentang Pemberantasan Tindak Pidana Terorisme.

Sumber bahan hukum sekunder yaitu suatu bahan hukum yang bersumber dari penelitian kepustakaan yaitu sumber bahan hukum yang diperoleh tidak secara langsung, melainkan bersumber dari data-data yang sudah didokumentasikan, buku-buku, artikel, majalah, internet, dan hasil-hasil penelitian yang berwujud laporan dan lain sebagainya, yang berkaitan dengan yang dan hubungannya dengan rumusan masalah yang dibahas.

\section{HASIL DAN PEMBAHASAN}

Kepolisian Negara Republik Indonesia yang berikutnya disingkat menjadi Polri adalah institusi yang mempunyai tanggung jawab di dalam mengupayakan, mencegah, mengeliminasi, dan melakukan deteksi dini di setiap gejala maupun penyakit masyarakat yang bisa saja timbul yang dapat menyebabkan terganggunya keamanan dan ketertiban di dalam masyarakat (Bonger, 1982). Anggota kepolisian pastinya mempunyai tugas yang bisa dikatakan cukup berat dalam usaha pre-ventif atau yang biasa disebut pencegahan dalam terjadinya pelanggaran, kejahatan, penyakit masyarakat, juga melindungi serta mampu untuk menertibkan masyarakat.

Dalam Undang- Undang Kepolisian Negara Republik Indonesia Nomor 2 Tahun 2002 tentang Kepolisian Republik Indonesia, "Polisi adalah aparat penegak hukum yang bertugas sebagai pemelihara keamanan, ketertiban masyarakat". Polisi adalah ujung tombak dalam integrated criminal justice system, ditangan polisilah terlebih mampu mengurangi gelapnya kasus kejahatan. Sebagai petugas Polri dituntut untuk menunjukan sikap yang tegas dalam menjalankan tugas dan wewenangnya sebagai seorang anggota Polri. Jika ditemukan adanya anggota Polri yang dalam bertugas tidak mampu untuk tepat dalam menentukan atau mengambil sikap, maka bukan hal yang tidak mungkin sebagai anggota Polri akan mendapatkan hujatan dan celaan dari warga masyarakat. Oleh sebab itu sebagai anggota kepolisian setiap menjalankan tugas dan wewenangnya haruslah berlandaskan pada etika moral dan hukum, dan harus menjadi komitmen dalam diri sendiri dan di dalam hati nurani setiap anggota Polri, sehingga anggota Polri dalam mengemban tugas, fungsi dan wewenang kepolisiannya dapat menjadi lebih baik lagi dari sebelumnya. Dengan begitu terwujudlah konsep good police sebagai prasyarat menuju good-governance.

Kewenangan dari Kepolisian Negara Republik Indonesia yang telah tercantum dalam Pasal 15 dan 16 Undang-Undang Kepolisian negara repubik indonesia yaitu tentang perincian mengenai tugas dan wewenang Kepolisian negara Republik Indonesia, sedangkan yang tercantum pada Pasal 18 berisikan tentang diskresi Kepolisian yang berdasarkan kepada Kode Etik Kepolisian. Sesuai dengan rumusan fungsi, tugas pokok, dan wewenang anggota kepolisian yang telah diatur dalam UU Kepolisian No. 2 Tahun 2002, maka fungsi utama dari kepolisian negara republic Indonesia:

a. Tugas kepolisian dalam Pembinaan masyarakat (Pre-emtif), merupakan segala bentuk upaya dengan melakukan kegiatan pembinaan masyarakat untuk meningkatkan kerjasama dengan masyarakat dan juga dapat menciptakan kesadaran hukum di masing masing masyarakat itu sendiri. Yang menjadi tugas anggota kepolisian yang dimaksud dalam bidang ini yaitu Community Policing, dengan melakukan pendekatan kepada warga masyarakat secara sosial dan hubungan mutualisme, maka akan tercapai tujuan dari community policing tersebut. Tetapi, konsep Community Policing itu sendiri saat ini sudah bisa dilakukan pelaksanaannya di Polres-polres. Seperti yang telah disebutkan diatas, agar dapat digunakan sebagai perbandingan atas sistem kepolisian yang berlaku dari Negara asing di luar Indonesia, juga harus melihat dari segi administrasi pemerintahan yang berlaku di negara luar, begitu pula sistem kepolisiannya dan juga berkaitan dengan karakter sosial masyarakat di negara luar.

b. Tugas kepolisian di bidang preventif, adalah segala usaha dan kegiatan yang dilakukan kepolisian secara preventif untuk menjaga keamanan dan ketertiban masyarakat, memelihara keselamatan orang, benda dan barang termasuk memberikan perlindungan dan pertolongan, khususnya dalam mencegah terjadinya pelanggaran hukum. Dalam melaksanakan tugas, anggota Polri memerlukan kemampuan profesional dan teknik tersendiri contohnya melaksanakan patroli, pengawalan, penjagaan dan pengaturan. 
Empat syarat guna menciptakan Kepolisian Negara Republik Indonesia atau yang biasa disebut Polri yang kuat adalah mempunyai sistem organisasi kepolisian yang baik, kesejahteraan kepolisian (welfare), politik, dan negara hukum yang mendukung. Welfare mencakup kesejahteraan dan sarana prasarana anggota kepolisian. Dengan histori, Kepolisian Negara Republik indonesia adalah lembaga birokrasi tertua di Indonesia, yang dibentuk oleh BPKI (Panitia Persiapan Kemerdekaan Indonesia) tanggal 19 Agustus tahun 1945, hanya 2 hari setelah Proklamasi Kemerdekaan Republik Indonesia. Berdasarkan dengan Undang-Undang Dasar tahun 1945 Indonesia merupakan negara kesatuan maka sejak tanggal 1 Juli tahun 1946 kepolisian negara republik indonesia juga menjadi Kepolisian Nasional dalam satu komando. Efektivitas sistem ini sangat nyata, kepolisian negara republik indonesia telah sanggup membentuk komando satuan kepolisian sampai dengan tingkat kecamatan di seluruh negara kesatuan republik Indonesia (NKRI) dengan jenjang hirarki yang jelas, yaitu Markas Besar Kepolisian Republik Indonesia atau yang boiasa disebut dengan Mabes Polri yang berpusat di ibu kota Jakarta.

Menurut Pasal 1 angka 4 Perkap Kapolri No. 3 Tahun 2015 tentang POLMAS adalah yang dimaksud dengan Bhabinkamtibmas merupakan anggota kepolisian yang bertugas sebagai pengemban fungsi Pemolisian masyarakat atau yang biasa disebut Polmas didesa/ kelurahan. Bhabinkamtibmas merupakan perubahan nama dari Babinkamtibmas (Bintara Pembina Keamanan dan Ketertiban Masyarakat). Sesuai dengan Keputusan Kepala Kepolisian Negara Republik Indonesia, tentang sebutan Babinkamtibmas (Bintara Pembina Keamanan dan Ketertiban Masyarakat) menjadi Bhabinkamtibmas (Bhayangkara Pembina Keamanan dan Ketertiban Masyarakat) yang di emban oleh setiap anggota Polri dari kepangkatan Brigadir sampai dengan Inspektur dan unit Binmas merupakan salah satu unit kerja yang di dalamnya merupakan aparat-aparat yang berfungsi sebagai Bhabinkamtibmas.

Konsep daripada Community Policing telah sesuai dengan karakteristik dan kebudayaan Negara Indonesia, dengan melaksanakan sistem keamanan lingkungan yaitu siskamling di desa nya masing - masing yang pelaksanaannya dengan cara bergantian antara masyarakat satu dengan yang lainnya di hari yang berbeda sesuai dengan ketentuan yang telah disepakati bersama dengan penuh rasa tangggung jawab atas kenyamanan dan keamanan di desanya masing-masing (Sztompka, 1993). Dalam kegiatan ini juga ditunjang oleh Kegiatan babinkamtibmas yang setiap saat wajib untuk selalu mengawasi daerahnya dalam pelaksanaan kegiatan-kegiatan khusus yang ada di desanya.

Bhabinkamtibmas adalah anggota kepolisian yang bertugas di tingkat desa sampai dengan kelurahan yang mempunyai tugas untuk mengemban fungsi Pre-emtif melalui cara yaitu dengan bermitra dengan masyarakat (Sinambela \& Dkk., 2006). Anggota Polri yang bertugas membina keamanan dan ketertiban masyarakat (KAMTIBMAS) dan juga merupakan pengemban fungsi Pemolisian Masyarakat (POLMAS) di Desa atau Kelurahan manapun. Contoh langkah kepolisian negara republik indonesia dalam menciptakan suasana Kamtibmas di tengah-tengah masyarakat yaitu dengan melalui Program Polmas. Polmas merupakan kegiatan dimana anggota Polri mengajak masyarakat melalui kemitraan antara anggota Polri dan masyarakat untuk ikut bersinergi bersamasama sehingga dapat mendeteksi sedini mungkin mengenai permasalahan Kamtibmas yang ada di lingkungan masing-masing juga dapat menemukan pemecahan dari masalah tersebut.

Berkaitan dengan teori peran oleh Linton dan Elder dan dihubungkan dengan peran Bhabinkamtibmas maka peran Bhabinkamtibmas di masyarakat, sebagai Babhinkamtibmas yang mengemban fungsi pre-emtif Babhinkamtibmas diharuskan dapat menjadi teladan dan pelindung bagi seluruh lapisan masyarakat mulai di tingkat masyarakat terkecil yaitu kelurahan ataupun di desa, selain itu pula seorang Babhinkamtibmas diharapkan mampu mendengarkan apa yang menjadi keluhan di masyarakat. Kegiatan keseharian dari seorang Babhinkamtibmas yang wajib dilaksanakan oleh Bhabinkamtibmas adalah dengan door to door atau yang biasa disebut dengan menyambangi atau melaksanakan kunjungan ke rumah-rumah warga desa maupun kelurahan yang menjadi tanggung jawabnya. Intinya, kegiatan yang dilakukan oleh seorang Bhabinkamtibmas adalah yang perlukan hanyalah $4 \mathrm{D}$ (Datang-Duduk-Dengar-Dialog) dan $1 \mathrm{C}$ (Catat).

Giat rutin Babhinkamtibmas dapat dilaksanakan kapan saja dan di mana saja. Kegiatan sambang tidak selalu harus dilakukan dengan kunjungan rumah- rumah warga, sambaing bisa dilakukan di warung/toko, di lapangan, dan lain-lain. Bhabinkamtibmas adalah ujung tombak dari kepolisian untuk mensosialisasikan pencegahan paham radikalisme kepada warga masyarakat di tingkat desa sampai kelurahan. Babinkamtibmas memberi tips kepada masyarakat untuk selalu berkumpul dengan anak- 
anak mereka saat makan. "Karena anak-anak yang mudah terpengaruh adalah anak yang labil, tidak diperhatikan, dan krisis akan identitas sendiri. Bhabinkamtibmas juga menjelaskan soal pengertian radikal dan bahayanya jika radikal menjadi bagian dari kehidupan bermasyarakat. Babinkamtibmas juga mengajarkan soal kontra radikal itu kepada pemuda-pemuda desa, Bhabinkamtibmas khususnya yang bertugas di wilayah hukum Polsek Denpasar timur ini juga menampilkan sebuah video tentang kejadian pengeboman di Indonesia. Di antaranya tragedi bom di Kedutaan Besar Australia di Jakarta pada 2004, bom Bali, dan bom Hotel JW Marriot. Pihaknya mengedepankan peran Babinkamtibmas dalam melakukan pencegahan paham radikal. Caranya bisa melalui sistem dari pintu ke pintu atau door to door dan kegiatan intera ksi dengan masyarakat lainnya. Kami juga berfokus pada generasi muda, misalnya dengan membentuk patroli keamanan sekolah, ujarnya. Upaya kami bukan teoritis saja tapi bagaimana kami bisa menyentuh hati dan menggugah masyarakat supaya mereka bisa membentengi diri dari paham radikal yang dewasa ini sudah sangat meresahkan seluruh lapisan masyarakat.

Saat ini di Negara Indonesia bisa dikatakan tengah darurat di tiga hal, yaitu darurat narkoba, darurat kebebasan, dan yang paling meresahkan masyarakat yaitu darurat akan paham radikalisme diharapkan Polri, TNI, pemerintah daerah, dan seluruh stek holder untuk saling berinteraksi dalam menjaga Negara Kesatuan Republik Indonesia (NKRI). Namun peran masyarakat juga sangat dibutuhkan dalam hal ini, bahwa setiap unsur harus terlibat karena ini menyangkut tentang hak kehidupan orang ban yak. Tidak hanya bisa dilakukan oleh kepolisian dalam hal ini Densus 88 (Santoso, 2018). Di antara paham-paham radikalisme yang bisa dilihat kasat mata yaitu intoleran, tidak mau menghargai orang lain (Afadlal \& Dkk., 2005). Selain itu ada juga contoh radikal lainnya yaitu radikal fanatik, eksklusif, dan revolusioner.

\section{SIMPULAN DAN SARAN \\ Simpulan}

Berdasarkan uraian di atas ada beberapa hal yang dapat disimpulkan terhadap Babhinkamtibmas dalam menjaga keamanan dari paham radikalisme bahwa:

1. Usaha Babhinkamtibmas dalam menjaga keamanan dari paham radikalisme:

a) Mengadakan kunjungan ke rumah-rumah warga guna mendengarkan keluhan masyarakat jika ada permasalahan Kamtibmas;

b) Memberikan bimbingan juga penyuluhan hukum dan Kamtibmas agar masyarakat dapat menjunjung tinggi Hak Asasi Manusia (HAM);

c) Mengajak warga masyarakat untuk melaksanakan siskamling dalam rangka mengamankan lingkungan;

d) Menggelorakan kegiatan warga desa maupun kelurahan yang bersifat positif.

2. Faktor-faktor penyebab berkembangnya paham radikalisme adalah:

a) Kapitalisme Global dan Problem Kemiskinan;

b) Pemahaman agama;

c) Sosial Politik;

d) Faktor Ideologis Anti Westernisme;

e) Kebijakan Pemerintah;

f) Faktor Pemikiran;

g) Faktor Psikologis; h. Krisis Identitas;

h) Keterasingan secara Sosial dan Budaya.

\section{Saran}

Dari kesimpulan sebagaimana tersebut diatas maka ada beberapa hal yang dapat diajukan sebagai saran dalam Babhinkamtibmas dalam menjaga keamanan dari paham radikalisme yaitu:

1. Kepada anggota kepolisian yang memiliki tugas di desa sampai di tingkat kelurahan (Babhinkamtibmas) sebagai pengemban fungsi preventif dan Pre-emtif diharapkan hendaknya terus meningkatkan upaya-upaya kepolisian dalam bermitra dengan masyarakat dan melakukan deteksi dini guna mencegah berkembangnya paham radikalisme di wilayah hukum polsek Denpasar timur. 
2. Kepada Pemerintah dan Masyarakat diharapkan untuk ikut turut andil dalam memberantas radikalisme. Masalah radikalisme perlu ditangani bersama-sama, tidak hanya Polri, Seluruh stake holder, pemerintah, elemen masyarakat, dan pengurus lingkungan juga dibutuhkan perannya guna mencegah semakin berkembangnya paham radikalisme.

\section{DAFTAR PUSTAKA}

Afadlal, \& Dkk. (2005). Islam dan Radikalisme di Indonesia. LIPI Press.

Bonger, W. A. (1982). Pengantar tentang Kriminologi. Ghalia Indonesia.

Jainuri, A. (2016). Radikalisme dan Terorisme. Intrans Publishing.

Kansil, C. S. . (1989). Pengantar Ilmu Hukum dan Tata Hukum Indonesia (Delapan). Balai Pustaka.

Mustofa, M. (2007). Metode Penelitian Kriminologi. FISIP-UI Press.

Odea, T. F. (1996). Sosiologi Agama, Suatu Pengantar Awal.

Santoso, A. (2018). Polri Andalkan Bhabinkamtibmas Tangkal Radikalisme. DetikNews.

Sinambela, L. P., \& Dkk. (2006). Reformasi Pelayanan Publik: Teori, Kebijakan, dan Implementasi. Bumi Aksara.

Sztompka, P. (1993). Sosiologi Perubahan Sosial. Prenada. 